\title{
Dialogue 3: Implications, challenges and opportunities of ODA graduation for DAC donors
}

ODA graduation does not only affect the transitioning countries themselves, but also has consequences for international partners or 'traditional' providers of international development cooperation, in both practical and strategic terms.

Most of the so-called traditional donors are or have been engaged in middleincome countries that are on their way to ODA graduation. Governments and implementation agencies are therefore confronted with the practical considerations of accompanying and cooperating with partners in that process. Here, we aim to exchange concrete examples of managing transition, based on the participants' experiences in practice and research.

We also want to analyse the strategic and political implications of ODA graduation. Working in global partnerships is not only essential to implementing the 2030 Agenda, therefore embodied in SDG 17, but has also been the modus operandi with many countries envisioned to graduate from ODA in the upcoming years. How can long-term relationships be secured when development actors withdraw? And what does a shift in the range of development countries mean for the actors involved, the systemic set-up of the policy area and the way that implementing institutions work?

In addition to the specific situation of partner countries graduating from ODA, the discussants shared general experiences from restructuring or phasing down development cooperation as a result of policy decisions.

The discussion was held between Corinna Küsel, Director of the Regional Division South Asia at GIZ, Annalisa Prizzon, Senior Research Fellow at the Overseas Development Institute (ODI), and Anna Rahm, Head of Unit for Effective Aid Delivery at the Swedish International Development Cooperation Agency, Sida. It was facilitated by David Nguyen-Thanh, Head of Division for Corporate Policy, Strategy and Risk Management at GIZ, and Juliane Kolsdorf, editor of this publication. For logistical reasons, the experiences of the Swiss State Secretariat for Economic Affairs (SECO) were added in a separate interview with Ivan Pavletic (Head of Section Policy and Services) and Markus Schrader (Head of Section Countries and Global Portfolio) and subsequently merged into the dialogue. ${ }^{68}$

68 For better distinction from the discussants, the inputs and questions by the facilitators are displayed in italic without naming the respective person. 
As a starting point, could you each briefly share the context or situation in which you have been involved with ODA graduation issues? How has it affected your work in recent years, and even today? Corinna, what does this mean for you and for GIZ these days?

Corinna Küsel: I would like to focus initially more on a perspective 'beyond ODA' before I come to a 'post-ODA' view because I think there are big differences in how relevant this is in general, and also for us in GIZ. By 'beyond ODA', we define everything beyond classical development cooperation. 'Beyond ODA' is already very much a normality and part of our daily life in GIZ, particularly in our cooperation with Asia and Latin America. In both regions, we implement various projects which go beyond a classical development cooperation approach, both for the Federal Ministry for Economic Cooperation and Development (BMZ) and for other German ministries and other donors. One example would be the Ministry for the Environment, with projects related to environmental and climate issues, i.e. on global public goods, such as climate change and biodiversity. We work for the Foreign Office on security issues, for instance in cooperation with regional partners like ASEAN, and also for other German ministries. The focus of these projects is strongly related to the relationship between Germany and our partner countries with a view to building partnerships, also in Germany's interests. These forms and areas of cooperation are generally much more related to German or European interests on the one hand and to global interests and global public goods on the other, and less focused on a classical aid perspective. This is the case for German ministries, but also for projects which are partly co-funded by other development partners. One example is the 'NAMA Facility', a multi-donor initiative supporting partner countries to implement climate-related projects - 'Nationally Appropriate Mitigation Actions' - which is co-funded by different European donors. ${ }^{69}$

For GIZ, this has always been part of our diversification strategy, of our strategy to change from development cooperation to a broader concept of international cooperation. This was also reflected in the changing of our name in 2011. However, at the same time, a large part of this work is still funded by ODA funds. I mentioned the other German ministries, but BMZ also supports various projects which go beyond traditional development cooperation: they are related to aims and goals on global public goods, but also to strengthening partner countries in their transition process. Examples are trilateral cooperation projects or advice to our partners in strengthening their own development cooperation agencies. For example, from my experience in Mexico, we had and still have a project to enhance the capacities of the Mexican Development 
Cooperation Agency AMEXCID, which has been highly valued as a contribution to strengthening Mexico in its role as an international and regional player. As a brieffollow-up question: To what extent has this GIZ role been shaped by commissions or desires by BMZ to look into these issues? In other words: Has this very much been a GIZ-driven interest to position ourselves beyond ODA? Corinna Küsel: For BMZ, it has always been part of its strategy to cooperate with 'global partners' and to strengthen them in their global role. Their strategy was very clear that working with these countries should not be traditional development cooperation but should focus on climate and biodiversity issues, on strengthening their development cooperation agencies and on enhancing their cooperation with the private sector as a third pillar. At the same time, it has been the German government's decisions to amplify the role of GIZ as an agency that also works for other German ministries as well as other European and international donors. But of course, GIZ has also actively pursued this diversification path.

Anna, we are most curious to hear about the Sida perspective: What is the relevance of ODA graduation to your organisation?

Anna Rahm: We have not really developed a strategic policy for graduation so far. It is not that this issue has been unnoticed by Sida or that we have not exited from several countries, but I would say that, at present, it is not a discussion that is actively ongoing at Sida.

When it comes to the steering selection of countries, it is, of course, a political decision which lies with the Ministry for Foreign Affairs. We can see that there has been a stronger focus in the past ten years or so on conflict-affected countries. We still aim to reach the poorest and most vulnerable, which means that we have rather broadened our portfolio of countries that are not moving in the direction of becoming middle-income countries. Therefore, we also have a much stronger focus on countries which are still very much dependent on aid. ${ }^{70}$

Our strategies generally reflect the needs as expressed in national development plans, and we strive to focus on the most important sectors and impact areas from the perspective of poverty reduction and vulnerability. So, in general, we have untied aid, and the Swedish interests of, for instance, trade investment have a very limited impact on the choices in development cooperation. We have other agencies in Sweden that we collaborate with and that work more in this grey zone of development and trade and investment. However, there are examples and ongoing activities in several countries, where we work on how to link trade and development cooperation in a more explicit way. We did phase

70 While many of Sida's partner countries are on their way to reach lower-middle or middle-income status, they continue to receive relevant amounts of aid and therefore remain dependent on ODA in various sectors. 
out our collaboration in India, Indonesia, China, Vietnam, Botswana, Namibia and South Africa between 2008 and 2013. The process that we carried out in the phasing-out of those countries was what we called partner-driven or actordriven cooperation. This means we tried to use the remaining years of development cooperation to reach out to other groups in society and broaden our way of looking at development so that we could leave a basis for sustainable development with more actors than the government and some civil society organisations. For example, we had more collaboration with trade unions and private companies. The reason for our withdrawal from these countries was mainly that we did not see that they were in as much need and we were entering into more conflicted-affected areas.

This reflects a broader shift among many development partners, donors, over the past few years. Interestingly, your phase-out happened up to 2013, which is prior to the 2030 Agenda. Has there been any rethinking since 2015 in terms of some of these middle-income countries becoming more interesting to Sweden again?

Anna Rahm: Well, to my knowledge, there are no real indications of that. Rather, there has been a discussion that more countries might be phased out in the coming years. For several years, whenever our strategies have been extended, there has been a discussion on these countries: Is this going to be the last strategy and what will that mean in terms of our focus in those countries? It is an interesting question, but these decisions are taken by the Ministry for Foreign Affairs.

Markus and Ivan, in which contexts or situations has the topic of ODA graduation and also cooperation beyond aid affected SECO's work in recent years and what relevance is given to the topic from your perspective?

Ivan Pavletic / Markus Schrader: The contexts are various and somewhat different. SECO underwent a strategic shift in 2008 when we decided to focus on middle-income countries. This was motivated by a clearer division of labour between us and the Swiss Agency for Development and Cooperation (SDC) ${ }^{71}$, which manages the bigger share of Swiss ODA. SDC focuses on least developed, low-income and fragile countries. The leverage and impact of SECO's economic development cooperation is higher in middle-income countries. As a medium-sized donor SECO needs to make a good case for its engagement in middle-income countries, also towards the partner governments. It is important to identify those niches where SECO can add value. This is a continuous effort. We are trying to focus on activities that add value, are complementary to SDC, and differentiate us from other donors. Foreign Affairs. 
Moreover, we have to explain to the public why we are engaged in middleincome countries; the rationale behind our engagement is important. We include this in the strategic frameworks that we submit to our parliament, saying that those countries play an important role in their regional context both from an economic and a political perspective, but also regarding their contribution to global challenges. This has been well received and understood by the public because, at the end of the day, there is also something in it for us. In addition to genuine Swiss long-term interest, it also offers economic expertise to overcome the so-called middle-income trap. Assistance to Least Developed Countries is very valuable and nobody disputes these countries' great need for ODA. But does this mean that should we neglect middle-income countries - which are on the verge of graduating but have not yet done so; or is there not also a genuine interest among the broader global community to support these countries? They are our partners in trilateral cooperation or cooperation beyond aid and are key or in assisting neighbouring, less developed countries, like Poland with Ukraine, or Colombia with Venezuela. With a relatively small investment, we can have a big impact.

In a way, we are close to 'beyond aid' with the way we work and the very nature of what we do. The countries we are active in are Indonesia, Vietnam, South Africa, Ghana, Peru, Colombia and, since the Arab Spring, increasingly Tunisia and Egypt ${ }^{72}$. None of them is under immediate 'threat' of being removed from the list of recipients of the OECD DAC but, at the same time, they are at different stages in their development as middle-income countries. Some are even G20 countries. Another example is when a government uses the 'beyond aid' narrative by itself, like Ghana. We highly welcome this in our cooperation, because that is the direction we would like our partner countries to go.

Yet, Swiss economic development cooperation in those countries is not primarily appreciated due to the amount of funding - the amounts are different compared to partners with higher ODA volumes - but because we bring specific experience and expertise, which countries can use to leverage other initiatives. One is: we can help you to spend your own money better. That is already closer to 'beyond aid' than general budget support. On the other hand, we invest a certain kind of risk capital. Partner countries may be hesitant to invest in - presumably helpful - development initiatives because their impact is still uncertain, and it would be hard for them to justify such spending to their taxpayers. However, if the initial investment is covered by Swiss funding, with a proven effect they can happily take over and finance it with their own means.

72 In addition, but with a slightly different reasoning, SECO is engaged in transition cooperation with Tajikistan, Kyrgyzstan, Ukraine, Albania and Serbia. 
Annalisa, could you put what has been said into the broader context of your research? Maybe you can add some particular insights from the various exchanges you had with development partners over the past few months. What is your perspective?

Annalisa Prizzon: We started working on this about four years ago. Back then, transition from aid and graduation from ODA were, to a certain extent, a taboo, the former often being a political decision. However, in order to avoid jeopardizing development results achieved, we need to translate the transition from aid into principles and approaches, even though it may not necessarily be a priority within a government or an agency.

First of all, while the transition from aid might be a relatively new concept, we should not overlook the other side of the coin: the criteria for aid allocation. Many bilateral agencies have aid allocation policies and criteria, with indicators surrounding needs, for instance on poverty or other dimensions of human development. And when these indicators improve, the envelope allocated to certain countries tends to fall. So, we should not think about transition from aid as a new concept. De facto, that was happening when different criteria were applied to the allocation of aid across countries.

However, there are a few elements that actually changed the narrative when it comes to the debates on exit from bilateral programmes. In recent years, many bilateral donors faced budget cuts or the reallocation of resources to other government departments. But it is also about increasing scrutiny on budgets for development cooperation. For instance, in the UK, about ten years ago, the rational for assistance to middle-income countries was put to the test.

But we should also acknowledge some progress. The number of low-income countries was about 60 ten years ago, and now if fell by almost half. While income per capita is not necessarily the best proxy to measure access to international capital markets, it is usually a good benchmark. All in all, governments' access to international capital markets has improved, expanding the volume of finance and shifting towards less concessional (and more expensive) financing instruments and modalities than traditional aid.

Three or four years ago, hardly any donor had a strategy on transition in place - probably the only one was the European Commission with the Agenda for Change in 2011, with a nuanced approach for the Development Cooperation Instrument. Nowadays I could name a few more development partners that have defined or are about to define principles for transition or exit from bilateral programmes. For example, USAID has now a strategy called "A journey to selfreliance", whose name is quite eloquent. In the end, country partnership strategies have the ultimate, albeit implicit, objective to support countries to develop and move away from aid. In the case of USAID, there are specific indicators that measure such process and define how USAID can best support those 
efforts. It is not necessarily about defining a strategy to cut aid flows. DFID is another example. In the UK, the Independent Commission for Aid Impact runs regular reviews of how DFID operates. One of them was on transition and exit from bilateral programmes. ${ }^{73}$ The analysis of DFID's approach prompted a request to specify the principles of transition. The system of Swiss Development Cooperation is developing a similar approach as well.

So, three, four years ago, probably only the multilateral development banks, the vertical health funds and the European Union may have had transition and graduation criteria and policies in place. Nowadays, we can see many more bilateral donors that are considering the implications of transition and exit from bilateral programmes in the definition of their country programmes and in their overall strategy, as well as they are defining principles on how to operationalise transition and exit from bilateral programmes.

With a number of bilateral and multilateral donors out there who have given themselves such a strategy, what are the lessons learned from their experience? For those donors who are yet to define their own strategy, what are recommendations in terms of what they should look at? What should they consider when cooperating with countries that are in the transition phase of graduating from $O D A$ ?

Annalisa Prizzon: These are often internal discussions. But if I were to summarise the two main elements, the first one is about planning, and the second one is communication. On planning, I could name a few positive examples. One of them was Sida, but also DFID and SECO, all of them in Vietnam as well as Denmark in India. Two of the key elements of the success in terms of transition from aid across these samples was first the ability to hand programmes over to other development partners or to the government without disruption and second the long-term planning. By long-term, I mean three to five years. In the case of Sida in Vietnam, the long-term approach meant mapping what other development partners were doing and the needs of the country, but also planning the medium-term request from the government and identifying who was going to take the partnership over. This could be done by other parts of the governments, like the climate or environmental ministry, or the trade ministry, but also civil society or, in a few examples, a multilateral development bank or a multilateral donor within the parameters that I mentioned earlier on.

About communication: there was a very interesting point that emerged in the case studies that we conducted in 2019 in the "Moving from aid" report ${ }^{74}$. Yes, the decision to leave and phase out the country was communicated to the

74 Calleja/Prizzon 2019a. 
government. But when we were talking with the government, some actors acknowledge that, at that time, they were not aware of it. So, the communication should be two-way and verified. We know that each government is a big entity and we should be concrete. Usually, we are talking about the Director of the DG Cooperation within a Foreign Affairs ministry. Line agencies should be informed too about a programme being phased out. I can give you an interesting example from Chile which is outlined in the case study. Many donors communicated that they would phase out their programmes, for instance BMZ (but also DFID with cooperation moving to the FCO), but the government did not necessarily consider the long-term implications of programmes being phased out at that time. The alarm bells only began ringing when the European Union announced that they would phase out the Development Cooperation Instrument. That was the moment when the government started trying to get the European Union back on board and also to challenge the criteria for ODA graduation within the OECD Development Assistance Committee.

This is quite an excellent assessment, Anna, of Sida's performance back then in Vietnam. Do you want to add to that or share another example of how you managed the phase-out? What were the key issues that guided your work in moving out and phasing down your portfolio in these countries?

Anna Rahm: One thing that we started to experiment with and learn more about in those countries is something that we have picked up and started to do in other countries as well: it is to take on a role as facilitator, which means that we both facilitate partnerships between actors - we may create platforms for actors to meet - and ensure a broader view on who should be involved in discussions about how specific development problems could be solved or how development could take place. In Vietnam, but even in other countries, we started to take on such a role a few years ago.

This includes making sure that private funding is involved in achieving development objectives, for example by sharing risks, but also by creating winwin opportunities. In 2007 / 2008, we developed some 'tools', and I know that GIZ and other agencies have also experimented with these. These are the public-private development partnerships, challenge funds, guarantees and different types of business development funds. These have been a way for us to make it interesting for the private sector to be involved and invest in areas where they would not have been involved otherwise, but also to look into new business models at times. We have sometimes been mediators in making sure that the private actors and the government discuss, that the government involves the private sector and invites them to be part of policymaking and discussions about industrial policy, for example. Sida has not done this alone; it was in partnership with many other bilateral actors, but it was a shift in these countries that we started to think about this role-not necessarily just in the phased-out countries. 
In Zambia, where I worked for a few years, we were trying to identify links between the trade section and the development sections of the embassy, so we arranged breakfast meetings with various actors from the society to talk about development problems. Today, in our new vision for Sida, it has been highlighted that we should have this facilitative role more often and try to understand how we can be that actor.

You obviously did not choose to abruptly discontinue work and move out, but, as you said, get involved in these facilitation platforms, etc. Although for those countries that until then had received substantial funds from Sida, it may be hard to adjust to a situation where you 'only' facilitate. How was that shift received by these countries?

Anna Rahm: There are certainly different situations, but most serious discussions were with the governments in these countries, because in many countries we had general budget support or at least sector budget support; we supported the governments in various ways. We worked a lot on capacity-building with sector ministries or large departments, so that has been a source of secured funding for many of these agencies for a long time. There was a big debate on how we can make sure that the funding that we withdraw will be covered from other sources quickly enough. In some countries, for example on tax reform, we have been collaborating with other bilateral actors engaged in that matter and trying to work on developing the capacity of governments to set up a firm taxation system that can generate enough income to at least maintain the basic structures of governments. But I think the discussions with the governments have probably been the most serious ones - although many of the civil society organisations that we work with suffered a big blow from not getting funding anymore as they may not have other sources of funding to draw on ${ }^{75}$.

Ivan and Markus, Annalisa just mentioned that SECO is working right now on principles of transition. Could you elaborate a bit on this process?

Ivan Pavletic / Markus Schrader: We have certain basic principles of how and when we engage with countries and we will put these forwards as a proposal for criteria to enter but also to leave a country with our ODA means. The first criterion is the country's needs. The second one is: do we as Switzerland bring an added value? Why does it have to be Switzerland? How do we make a difference, given our nature and the instruments we have at hand? And the third one, which has been in place since 2006: How will it benefit Swiss interests? We have a strong middle- or long-term interest in working with these countries because with a stable, well-functioning country like Ghana, we also create markets and we can also trade with these countries. In today's globalised world,

75 For an extended analysis of this matter, see Rachel Hayman's contribution on the role of civil society in transition in this publication. 
any country's 'failure' will have global repercussions, and we will all be better off, including Switzerland, if countries around the globe develop well in an economic sense.

Apart from that, we developed two further criteria for cooperation. The first is that the country needs to figure on the OECD DAC recipients list. Otherwise it does not qualify for ODA and would not be in our mandate. That is a crystal clear one. And second, we prefer to work with countries where certain minimum standards exist in terms of economic governance, human rights, and the willingness and potential to reform. These criteria are rather minimal, but we cannot work in countries at war or where it is highly difficult to be active as a development partner. There also needs to be a certain reform willingness in the area of work that we are in. If the country does not want us or if there is an interest but no willingness to reform on a political level, why should we be there? We are not desperate to just stay and hang on with that country. There are many more countries which show this willingness, and we should work with champions and those eager to cooperate with us and to incorporate the joint lessons learned. The last one, apart from the reform willingness, is the potential for reform, which is yet a different aspect.

We try to provide a few clear-cut criteria and, within them, to understand what our priorities are and develop a certain subset of criteria, which makes it possible for us to evaluate the remaining countries.

The process of transition does not happen overnight, and many of us operate in contexts where partner countries grow into middle- or high-income status but still qualify for ODA. Corinna, in addition to your initial input: What does this mean for us? What are GIZ's modes of cooperation in these contexts? Do they change? For countries that are about to graduate in the next five, six, seven years, does GIZ work any differently compared to low-income or least developed countries?

Corinna Küsel: Cooperation with these countries definitely does change. I already mentioned that our focus is more on topics related to global but equally German or European interests. But also, the modes of cooperation change: our focus is much more on building capacities, advising on policies or processes. These countries are very demanding in relation to the expertise we provide, both technically and related to process management. Policy dialogues between Germany and its partner countries or building networks between these countries also play an important role. At the same time, funding as part of our cooperation becomes far less important as these countries often contribute funds from their own resources. Even in those countries which are not official partner countries of German development cooperation anymore, cooperation has been continued through regional or global approaches and funds. 
Following up on that, one of the findings in the ODI case studies was that the respective graduating countries all voiced their concern about possibly losing access to specific technical cooperation, knowledge exchange and policy dialogue. There was a strong interest in continuing cooperation in that sense. In your views, how can donors and implementing organisations address that very clear demand? How can technical cooperation still happen in circumstances where a country is yet or just about to graduate?

Corinna Küsel: We do have some experience with these modes. For various German ministries, we are already implementing projects to facilitate the dialogue between the respective partner country and the relevant German ministries and agencies. This is a different mode of operation in comparison to how we have worked in most countries in the past, but we use these forms of platforms and dialogue approaches.

Anna Rahm: In most countries where we have ongoing development cooperation, we have also had a parallel collaboration with other Swedish government agencies, such as the tax agency, statistics office, police and so on. They are not part of our strategy and we do not fund them directly, though sometimes indirectly. It is part of the government's agenda to broaden the number of actors that work with development, and also to include technical cooperation. Many of these types or means of collaboration continue even after development cooperation is phased out. In some of these countries, we still have ongoing partnerships in areas where we have a comparative advantage, and this is not limited to development cooperation.

Ivan Pavletic / Markus Schrader: We do not yet have very refined instruments, but a similar discussion. The question for us is: if we want to make a statement of 'mission accomplished' when exiting from a country, how can we make sure that this is not received as a loss in our partner country? We will probably do extensive mapping in our partner countries in order to understand better what other Swiss interests there are in this country. Obviously, our goal is still the economic development of the partner country, whereas the goal, for instance, of an export promotion agency is exploring new markets for Swiss SMEs. But it might be an interesting means for us to work with Swiss SMEs, which would be happy to export and to understand how we match supply and demand between the given country and the Swiss exporter. Another example are our projects on research and innovation on the one hand and academic cooperation on the other. If we clearly differentiate that our means are others' objectives and others' means are our objectives, we can find a potential win-win situation. So, how do we bring these countries to that level and how do we walk the last mile together in order to make this a fruitful form of cooperation and mutually reinforce what we do in order to bring about change? On the other hand, a danger in that undertaking may be to fall back into patterns of tied aid or into industrial 
policy questions where it is not so clear whether what you do is ODA or in the purely economic short-term interests of your own country. That is why I highlighted the differentiation between objectives and means and understanding how win-win works if you do it right. And that is currently where our mapping is at, so we cannot provide you with an answer yet.

Finally, we are exploring potential linkages between our technical assistance and the Swiss Investment Fund for Emerging Markets, working on an understanding of what would be a good way to go beyond grants. In addition, it is also very important to strengthen the links within SECO. For example, with the unit in charge of setting up free-trade agreements, we try to focus more on sustainability issues. Those are win-win situations where we can promote economic interests, free trade and make sure that international labour, and social and environmental standards are being implemented - as this is in the core interest of our partner countries. Through our projects, we then try to help stakeholders implement them on the ground. Going even further, the Department for Foreign Affairs is currently setting up a process to discuss regional strategies or strategies for priority countries. They invited several departments and units on a strategic level to see what their interests and added values are, setting up a government's approach in its entirety. This is very valuable because you see where the complementarities are and how each and every unit can contribute.

In the end, it also calls for the question of - and this is by no means an official Swiss position - if the ODA concept is still relevant. And if there are no other, better ways to measure donors' contributions to global challenges, especially also because the SDG 2030 framework is much broader than what the ODA concept would allow as a measure.

We have already started to touch on the strategic and political implications of ODA graduation for providers of development cooperation. Annalisa, could you share your perspective on how donors can continue to live up to the longterm, value-based relationships that have often emerged over many years of development cooperation. Obviously with ODA graduation, this is going to be disrupted in some way. How can some form of continuance be secured in a postODA setting, including the possibility of strategic partnering with graduated countries on global public goods?

Annalisa Prizzon: This is a very interesting question because we are somehow stuck in the old aid paradigm. There are many opportunities for policy dialogue, also within other government departments than the development units, but the funding attached to it creates incentives, the urgency and the opportunity to do that. Some of the modalities have already been mentioned, for instance regional cooperation approaches and, to a certain extent, triangular cooperation. 
Regional cooperation does not necessarily directly benefit the graduated country. But with regional cooperation projects you are working with neighbouring countries, cross-border projects that can indirectly benefit the country that has already graduated. That was a good way, for instance, in Chile to keep the policy dialogue with development partners open. Regional cooperation is also a learning opportunity for countries that graduated to become development partners themselves if they wish to do so, and in many cases, this is part of their own strategy.

Triangular cooperation was also mentioned earlier on. This was a modality, for instance, that Mexico development cooperation tapped into more frequently when the volume of ODA started falling. It was also one of the options in the case of Chile. There are challenges for the implementation of triangular cooperation programmes though. The first are very high the transaction costs. Another point is about the (lack of) visibility of some development partners involved. In the case of the Republic of Korea, which graduated from the list of ODA eligible countries 20 years ago, ${ }^{76}$ triangular cooperation became less important over the years because of the lack of visibility they had in this arrangement for development cooperation.

In addition, one of the key players in a post-ODA setting focusing on global public goods are the multilateral development banks. This is the case for many reasons. MDBs often had country offices and they stay on despite being small, so they have country presence. Paradoxically in the case of Chile, incidentally when the country was about to graduate from ODA, the World Bank and the Chilean Ministry of Finance set up an office as a research-oriented hub, which also meant the World Bank had a local presence. Multilateral development banks have different criteria for graduation. Of course, the terms and conditions of financing are not such that their flows can be counted as ODA, but that is still official finance and, in many cases, terms and conditions far better than what countries can get in international capital markets. The partnership of bilateral donors with multilateral development banks in a post-ODA setting is of paramount importance.

Given that multilateralism has come under attack in some way, including the fact that many multilateral development banks have in some way been questioned in recent years: to what extent do you think are they ready and fit for purpose given the expectation that you just outlined? Are they currently in a position to live up to what you said?

Annalisa Prizzon: In a short answer: yes, because they offer a combination of financing and, to a certain extent, also assistance to upper-middle-income countries. I am oversimplifying, but this can also help to subsidise the concessional 
window, that is, the assistance to the poorest countries. So, from a financial perspective, MDBs are fit for purpose, and from a technical perspective, their staff have a set of skills, capabilities and, in many cases, world-class knowledge across a large number of countries. They are often stronger than bilateral donors when it comes to technical assistance. MDBs have a relatively strong convening power, especially the World Bank. We also need to think about a fourth dimension. Earlier on I mentioned that graduating countries were not particularly concerned about financial resources. Their main concern was about the technical assistance that comes with financial assistance. For example, some countries could also tap into technical assistance from MDBs through reimbursable assistance services, meaning that country governments can purchase directly a certain kind of advisory services. Even if there are these challenges to the multilateral system, I believe that recipient countries still highly value the assistance and the terms of conditions they can get from MDBs, and also the policy dialogue they offer.

Ivan Pavletic / Markus Schrader: I can confirm that, for us, partnerships with multilateral development banks are very important and something that we will continue to strengthen over the coming years. Switzerland is represented in the executive boards of Multilateral Development Banks, such as the World Bank, and the regional development banks. We understand and support their agenda to bring about change and support economic development in their member countries, sometimes in a multilateral set-up, sometimes with additional bilateral support.

Anna, what does this look like from a bilateral perspective? I am sure that it is also important for Sweden to contribute and be part of the answer to address global challenges. How do you work on these issues, for instance with a country that has just graduated or is about to graduate, and what does this mean for your organisation?

Anna Rahm: I would like to echo that we work on a lot of the global public goods on several levels: global, regional and bilateral, and we try to often convene and work through multilaterals and joint networks of actors. When we work with climate funds, for example, the type of projects requires a large number of actors to be involved.

If I talk about it from a different angle, two of the general cornerstones of Swedish development cooperation are that we develop very strong ownership and that we work on capacity. Capacity is, of course, a broad concept, but our focus is particularly on strengthening the ownership of the most relevant issues, rather than trying to solve them ourselves with short-term fixes. For instance, we work a lot on strengthening the capacity of governments to be able to handle increased funds that can support aspects that include global public goods. However, we rarely work on these aspects only from a bilateral perspective. It is 
rather part of our regional portfolios and, almost without exception, with multilateral partners.

Corinna, you already talked about the work GIZ has been involved in with respect to global public goods, climate change, etc. for many years. Given that experience, what are the implications for GIZ's way of working and do you see a change in how we address these issues compared to 10 or 20 years ago? Corinna Küsel: Yes, I think there has been a change. First of all, the Ministry of the Environment only started to strongly focus on international climate funds ten or twelve years ago and, in addition, has increasingly given assignments to GIZ and other implementors. They also have a different perspective on how they expect us to work and, on the outcomes, they expect us to generate. At $\mathrm{BMZ}$, there was always a much stronger relationship between climate-related objectives and development-related objectives. And when we work for other agencies, there is also quite a different frame of objectives and goals and a strong expectation that we adjust to it. If you look back 10, 15 years, this has changed quite a bit.

One final question: if you look at the development cooperation system as we know it, what is the main opportunity and also the main risk or challenge that you see when it comes to the dimension of ODA graduation?

Corinna Küsel: From a corporate perspective, what would it mean for an organisation like GIZ if more and more countries graduated? For now, we have concluded that there are very few or limited perspectives for GIZ in countries that have graduated from ODA. Our experience is that in all countries in which we work, even if they are already on their path towards high income, BMZ usually continues to play a very significant role. As mentioned before, even where BMZ has officially phased out its bilateral cooperation, development work has continued through different funds, for example with regional or global projects. Therefore, we still see a significant share of BMZ funding in these countries. From a corporate view, it has been this combination of funds, some from BMZ, some from other clients, that has enabled GIZ to continue our cooperation in the respective countries. One of GIZ's key assets is our presence in these countries; we have a very strong implementation base. Our local office structures enable us to build new partnerships, to identify new donors and to cooperate with other agencies. A lot of the co-funding which we receive, for instance from Sida, the European Union or other bilateral or multilateral donors, is based on our presence in these countries. However, if BMZ was to pull out completely from these countries - due to them graduating from ODA, for instance - without investing in regional or global funds anymore, it could have serious implications for our mode of operation on the ground. 
In summary, at least for now, our analysis would be that there is a substantial risk. That may change if we talk about the graduation of big players like China or Brazil or Mexico, as in this case, Governments might consider new modalities and funds for cooperation, where GIZ might have a role in implementation. However, for now, I think ODA graduation is an area where we as an implementor see very limited prospects of us continuing cooperation in the respective countries.

Markus Schrader: I will take one step back and look at what motivated us to work in the middle-income countries, and it is very similar to the anchor country concept which BMZ developed at that time ${ }^{77}$. As long as middle-income countries are still eligible for ODA, we have a case to support these countries, which hopefully leads to economic stimulus for an entire region, with spillover effects into neighbouring countries and into regional stability. We strengthen relationships in contexts where, and here I see opportunities and probably some threats, regional economic federations are increasingly appearing. ASEAN would be one, the African Continental Free Trade Area would be another one, also MERCOSUR. So, we have different fora that already go beyond aid with an economic interest to see to it that we do not lose our importance and that we bring cooperation to another level. At the same time, we are currently discussing trilateral cooperation, in which we have not had so much experience so far: how do we leverage what we have achieved in these countries and their experience for activities in third countries? The approach which we have chosen so far is to strengthen institutions in the countries we are working with that are still ODA eligible. Just to name one example from South Africa: the National Treasury and the Revenue Service were overwhelmed by other African countries asking 'how do you go about public financial management and about broadening the revenue management, in the sense that their officers couldn't do their proper work anymore because they were so involved with providing technical assistance to neighbouring countries. So, they created spin-offs as international organisations which we supported as development partners to make the knowhow from South Africa available to other countries in the region. Through that, we still have them onboard as a partner. Another way of doing so, also with German co-financing, are the regional technical assistance centres of the IMF, which obviously not only ODA-eligible countries are part of. There are different forms of exchange and potential for peer learning, so we do not necessarily have to lose our impact and we do not necessarily have to hamper our relations with these countries if we are not able to spend ODA means any more in that country. https://www.bmz.de/en/service/glossary/A/anchor_countries.html (15.04.2020) 
In my view, the biggest threat and the biggest opportunity is the establishment of the SDGs and my question is: will we still have an ODA discussion, as we are having today, in 2025? It is not as clear-cut any more where to start and stop with ODA, but I presume that discussions will rather go into a format known from the World Bank - like who is IDA-eligible ${ }^{78}$ and who is not anymore, who receives loans, who has to repay how much - and that we will have a kind of 'solvency scale'.

Anna Rahm: This is a big question. We have talked about this on various occasions, and it comes up a lot when we talk about development effectiveness or aid effectiveness. That agenda used to be very strong. And now, if I start from the risk point of view, I see that there is increased fragmentation and that comes with the good thing of more actors being involved. We have new actors coming in that are not traditional donors and new streams of funding for development goals, so it poses a challenge that these new actors and new types of actors do not work in a similar way to traditional donors. And even the traditional donors have fragmented more. There were pros and cons in the traditional setting, but on the pro side we had the same rules of the game, and we tried at least to harmonise, to focus very much on ownership, to have a balanced view on results-based management and so on. So, in this respect it poses a risk that we now have a much more fragmented system.

Ivan Pavletic: I also think there is a risk in graduating countries not taking over the whole package we have built over the last 30-40 years with all the insights and lessons learned in the industry of international cooperation. It is important for the graduates to assume their responsibilities in the international community. We still have some issues there. If we are honest, the whole Busan-AccraParis Agenda is dead, and we have not replaced it with a framework that has a shared legitimacy among traditional with emerging donors. This is a challenge we need to address. And with this comes the question of coordination. We do not want or have to do what other donors are doing and, certainly, some competition is good for the industry, to challenge ourselves and learn about best practices. Yet, I think there needs to be some balance between competition and coordination. And from my perspective, we have not found this balance yet. We need, also within fora like DAC and others, to find such mechanisms because, while those questions have been discussed in the last few years, I do not think we have come to a good solution as of now.

78 The International Development Association (IDA) is the part of the World Bank that provides credits on concessional terms, i.e. with a zero or very low interest charge. Repayments are stretched over 30 to 38 years. Eligibility for IDA support depends primarily on a country's relative poverty, defined as GNI per capita below an established threshold and updated annually (1,175 US-dollar in fiscal year 2020). For more information, see: http://ida.worldbank.org/about (15.04.2020). 
Anna Rahm: We do have the SDGs that are leading us in the right direction, and it is very good to have the Addis Agenda on financing for development. And linking back to the opportunity, as bilateral actors, we have about 60 years of experience, of knowing what works and what leaves you with long-term effects and long-term results. So, because we do not necessarily have our own agenda, we could play a role of trying to assist actors to make the most of the funds and to leverage other funds. We also see a strong interest from private actors in collaborating with us on various issues because we have a lot of experience and knowledge. The leverage role of development or ODA could be utilised better. We could choose to have this broad agenda of working with everybody in all sectors and just try to facilitate, or we could decide to focus on our comparative advantage and just focus on the poorest and most vulnerable and try to fund the issues that no one else funds. It seems like many bilaterals, just like us, have not really decided which leg to stand on here, so we are doing a little bit of both. That could be our role as well, to really make sure that not leaving anyone behind is our part of the playing field.

You perfectly described the strategic challenge that many donors face and both themes are part of the 2030 Agenda, to leave no one behind but to also address global public goods through global partnerships. Annalisa, you have the final word and I think it is perfect to let the researcher speak from a broader perspective: Is there anything essential we have left out?

Annalisa Prizzon: I would like to reiterate the point that Anna just made. Rethinking or redefining what we mean by development or international cooperation would be of paramount importance. As Anna put it very clearly, there is a tension between aid in the old paradigm, that is, the poorest, the neediest countries in a grant financing format, vis-á-vis broader agenda for policy dialogues and pursuit of donors' national interest in wealthier recipient aid countries.

We should also go back to what we mean by ODA graduation because it is a binding constraint for many donors. The fact that assistance cannot be counted as ODA any more in certain countries is a clear disincentive for DFID, BMZ and French development cooperation. We do not have to elaborate why income per capita is a very limited measure to assess development, but this is still the criterion that the DAC uses to trigger and assess graduation from the list of ODA eligible countries. And we have seen, even in this project, how weak this measure can be. Countries can face shocks and see their income per capita falling, and this happened with some of the small island developing countries. In the case of Chile, the fact that graduation was defined on the basis of income per capita masked the large inequalities within the country. There may have been certain areas of Chile that could still have benefitted from development cooperation. I am aware there might not be a window to influence and change 
the criteria for ODA graduation. But based on the evidence of the limitations of the income per capita measure as a proxy for development as well as the vulnerability of many countries to shocks, I think there may be scope to rethink the criteria for the graduation from the list of ODA eligible countries. 
